\title{
Analysis of the Jet Engine Propulsion and Thrust relative to the use of the Water Molecule Power Reactor System
}

\author{
Cornelio Jeremy G. Ecle, Fedeliza O. Abrera, Arvin Anthony S. Araneta, Cherlowen A. Bolito, \\ Archibald M. Duran, Loren Rose L. Alforte, Arnold R. Balano, and Archibal D. Ranido
}

\begin{abstract}
As civilization evolves through time, humans had begun to unfold the capabilities of the mind to create things and it had evolved through the great span of time from ancient world to the modern era but human civilization cannot be considered advance yet until it is able to reach the nearest planet from earth. As human had begun to embrace the modern world of digital technology and space travel, it had become a burden for mankind as to how would it be able to reach the moon and the nearest planet from earth. The primary concern for space travel is fuel. The fuel that would be capable of transporting a ship from this planet earth to the next nearest planet in the solar system, the answer to this question might be here on earth as well, the very element that came from space and form our beautiful and amazing planet, it is water. Water is a very vital element to human existence although many take it for granted but water is truly our life and time will come that water will be a very valued commodity in this planet
\end{abstract}

Index Terms-Hydrogen, Oxygen, Water Molecule Power Reactor, Thrust, Jet Engine Propulsion.

\section{INTRODUCTION}

Water and the vast span of ocean is equally the same its water. This water would fuel our space ship to the next nearest planet here in the solar system. Thus water is the future of human civilization it will fuel our need for energy and the dream of reaching the stars. In this paper the researcher will examine the fundamental molecular and chemical characteristic of hydrogen and oxygen as being the prime elements present in water. Hydrogen and oxygen has a chemical property which is called the root mean square velocity which allows it to travel in a given distance if it is subjected to heat or burning, meaning it is able to create a displacement a change in position in a given point from an initial position to another position with respect to the change in time. This change in position is very essential to this

Published on June 30, 2020

Cornelio Jeremy G. Ecle, MIT, Eastern Samar State University, Philippines. (e-mail: jeremyecle2015@yahoo.com)

Fedeliza O. Abrera, MIT, Eastern Samar State University, Philippines. (e-mail: fedessabrera ${ }^{@}$ yahoo.com.ph)

Dr. Arvin Anthony S. Araneta, DMT, Eastern Samar State University, Philippines. (e-mail: arvin.araneta ${ }^{\circledR}$ gmail.com)

Cherlowen A. Bolito, MAT-MATH, Eastern Samar State University, Philippines. (e-mail: drrmessusalcedo@gmail.com)

Archibald M. Duran, MIT, Eastern Samar State University, Philippines. (e-mail: archie5_927@yahoo.com.ph)

Loren Rose L. Alforte, MIT, Eastern Samar State University, Philippines. (e-mail: lorenrosealforte2020@yahoo.com)

Arnold R. Balano, Eastern Samar State University, Philippines. (e-mail: arnold_balano18@yahoo.com)

Archibal D. Ranido, MIT, Eastern Samar State University, Philippines. (e-mail: archibalranidog1@gmail.com) study since this property can be a key factor for making water as a fuel of moving an object from point 1 to point 2 . To understand these properties this paper will examine some mathematical formulas so that it can be illustrated clearly the potential and future application of water as being a fuel of the future.

One of the many applications of the proposed Water Molecule Power Reactor System is in the areas of Jet Propulsion as a consequence of making the Water Molecule Power Reactor System to be able to generate electric power. Since making the Water Molecule Power Reactor System to be able generate electric power it will be directly connected to an electric turbine which will convert the energy of the Water Molecule Power Reactor into an electric energy from heat to electric energy. The prime driving force that generates electricity is the velocity that is created by burning a hydrogen gas and an oxygen gas as is present in water. Upon the separation of hydrogen and oxygen gas from water this gas is burned in the process and the process of burning creates a chemical reaction that triggers the gas explosion, and the burning process generates a thrust and these thrust moves the turbine propellers, and in turn produce electricity.

The formula of thrust [1] is as follows as shown below.

$$
T=v(d m / d t)
$$

Where:

$\mathrm{T}=$ Thrust Generated, (Force), Kilograms or Newton;

$\mathrm{v}=$ Speed of the exhaust gases, (Meters per Seconds);

$\mathrm{dm} / \mathrm{dt}=$ Rate of Change of Mass with Respect to Time;

As shown in the mathematical formula of Thrust it can be illustrated that Thrust is directly proportional or dependent on the speed of the gas being burned in the process which is in this paper it is the Hydrogen and Oxygen gas generated from the electrolysis of water inside the Water Molecule Power Reactor System.

The ability of the water to be able to generate electricity [2] by means of the Water Molecule Power Reactor System with of course the introduction of Potassium Hydroxide as a water conductivity additive. These properties of water is very unique and amazing in its natural form and wonder which is why the researchers of this paper have initiated this study further into its unbound potentials. Thus to say that the first property of water is to produce electricity [2] and the second property of water is to generate propulsion respectively, these two properties of water is a product of a single process which can be obtained through the system employed by the Water Molecule Power Reactor. 
All previous studies [5], [6], conducted by the research team of this paper where all relevant and interconnected even up to this recent research study. All previous studies conducted by the research team of this paper where all fundamental principles leading to the current study of jet engine propulsion principles. Thus some topics of the previous studies will be mentioned in this paper so that the readers would be able to catch up with the discussions.

In this present study the researchers will answer some of the relevant questions that need to be answered such as how, would the Water Molecule Power Reactor System be used for jet engine propulsion given that electricity [2] had already been produced as discussed in the previous papers.

The discussion of this research paper will be outlined as follows. The introductory discussion will be explained, the first subject to be tackled will be the Principles of Thrust. Second the paper will discuss the Principles of Root Mean Square Velocity or the velocity of gasses such as the Hydrogen and Oxygen. Third the paper will then correlate the Principles of Thrust and the Principles of Root Mean Square Velocity with respect to Jet Engine Propulsion Principles. Fourth the Principles of Jet Propulsion will then be discussed and its potentials to Planetary and Inter Planetary Travels. The fifth discussion will relate the Water Molecule Power Reactor System to Jet Engine Propulsion Principles and Potential Future Applications.

Thus this paper will now start the discussion as follows.

\section{RESEARCH PARAMETERS}

\section{A. Principles of Thrust}

Thrust is basically a movement of a mass of body in a vertical direction which is in the Cartesian Coordinate System it is in the $\mathrm{Y}$ coordinates from $-\mathrm{Z}$ to $+\mathrm{Z}$ respectively or vertical from land to air and from air to land or in this research from the earth to space and from space to earth.

The formula of thrust [1] is as follows as shown below as illustrated earlier.

$$
T=v(d m / d t) ;(\mathrm{Z} \text { Coordinates })
$$

Where: Newton;

$\mathrm{T}=$ Thrust Generated, (Force), Kilograms or Seconds);

$\mathrm{v}=$ Speed of the exhaust gases, (Meters per

Time [5], [6];

$\mathrm{dm} / \mathrm{dt}=$ Rate of Change of Mass with Respect to

On the other hand a movement or displacement of a mass of body in the horizontal direction is called Force. The formula of Force is as follows. From University Physics [1],

$$
F=m a ;(\text { Horizontal Movement, X Coordinates) }
$$

Where:

$\mathrm{F}=$ Force, (Newton, $\left.1 \mathrm{~N}=1 \mathrm{~kg} \cdot \mathrm{m} / \mathrm{s}^{2}\right)$;

$\mathrm{m}=$ mass of a body, (kilograms, $\mathrm{kg}$ );

$\mathrm{a}=$ displacement of a body, horizontal motion,

$\left(\mathrm{m} / \mathrm{s}^{2}\right)$
Thus from the two equations as shown above this paper have been able to differentiate and illustrate the two motions of a body in the horizontal and in the vertical point of view.

From the equations above this paper can illustrate that there is a burden in moving something from one place to another because of the inherent nature of the mass of the body being moved from one place to another. Thus mass [3] is a variable that this research will address to with respect to velocity and displacement because a mass too large to move cannot move at all without an equal amount of force that will move such mass into a given direction. Thus force or thrust must be greater or equal to the mass being moved around to a certain direction otherwise there would be no movement at all. To address this concern, this paper will discuss more on this matter as the paper goes along with the discussions.

Since it was mentioned in the above equation of Formula, the variable of acceleration, thus this paper will also define acceleration. Acceleration according to University Physics [1], it is written in the mathematical form as follows.

$$
\begin{aligned}
& a a v=\left(V_{2}-V_{1}\right) /(t 2-t 1) ; \\
& a_{a v}=\Delta V / \Delta t ;
\end{aligned}
$$

Where:

$\mathrm{a} a v=$ average acceleration, $\left(\mathrm{m} / \mathrm{s}^{2}\right)$;

$\left(\mathrm{V}_{2}-\mathrm{V}_{1}\right)=$ change of velocity from $\mathrm{V}_{1}$ to $\mathrm{V}_{2}$ respectively, (meter per second, $\mathrm{m} / \mathrm{s}$ ) [5], [6];

$(\mathrm{t} 2-\mathrm{t} 1)=$ change of time from $\mathrm{t} 1$ to $\mathrm{t} 2$ respectively, (seconds, s) [5], [6];

Acceleration will become an important variable as this paper will calculate later the value of force for the Hydrogen and Oxygen. The force will be our defining measure on how much force will Hydrogen and Oxygen gas exert so that it moves an object to a certain distance. Will the force created by the Hydrogen and Oxygen gas be sufficient enough to move an object with a mass of 1 kilogram. These questions will be answered by this paper and it will be answered as this research moves along with the discussion so therefore acceleration is an important variable if this paper will calculate the value of force created by the Hydrogen and Oxygen gas [3].

Another important variable to discuss is the Work. Work according to University Physics [1], is as shown in mathematical formula.

$$
W=F s ; \text { (constant force, straight-line displacement) }
$$

Where:

$\mathrm{W}=$ work, $($ Joule, $1 \mathrm{~J}=1 \mathrm{~N} . \mathrm{m})$;

$\mathrm{F}=$ Newton, $(\mathrm{N})$;

$\mathrm{s}=$ straight line displacement, (meters, $\mathrm{m}$ )

Work is very essential on the topic of jet propulsion since it illustrates the amount of force required to move a certain mass in a given direction.

Since from the subject of Thrust, velocity was mentioned, this paper will also define velocity to put the subject of Thrust into a clear perspective.

$$
v=(X 2-X 1) /(t 2-t 1)
$$


Where:

$\mathrm{v}=$ velocity,$($ meters $/$ seconds, $\mathrm{m} / \mathrm{s}) ;$

from $\mathrm{X} 1$ to $\mathrm{X} 2$

$\left(\mathrm{X}_{2}-\mathrm{X}_{1}\right)=$ the difference of the change of position

$(\mathrm{t} 2-\mathrm{t} 1)=$ the difference of the change in time interval from $\mathrm{t} 2$ and $\mathrm{t} 1$;

Thus from the above equation this paper can say that velocity therefore is a function of the change in position with respect to the change of time [5], [6].

Now therefore this paper, have completed the initial explanations in relation to the principles of Thrust as being the prime concern of this study.

\section{B. Principles of Root Mean Square Velocity}

Root Mean Square Velocity is a property of an element that is a function of the Temperature, Molecular Mass and Ideal Gas Constant [3], particularly elements which are gaseous in nature. Gas tends to create a force upon interaction with heat which is why Root Mean Square Velocity is a very important mathematical formula in understanding gaseous elements and their behaviors.

The formula of Root Mean Square Velocity is written as follows.

$$
\begin{aligned}
& \mu r m s=(3 R T / M)^{1 / 2} ; \\
& \mu r m s=\sqrt{ }(3 R T / M) ;
\end{aligned}
$$

Where:

$\mu \mathrm{rms}=$ root mean square velocity, $(\mathrm{m} / \mathrm{s}) ;$

$\mathrm{R}=$ ideal gas constant, $\mathrm{R}=8.3145$

$\left(\mathrm{kg} . \mathrm{m}^{2} / \mathrm{s}^{2}\right) / \mathrm{K} . \mathrm{mol}$;

$\mathrm{T}=$ absolute temperature in Kelvin, $(\mathrm{K})$;

$\mathrm{M}=$ mass of a mole of gas in kilograms $(\mathrm{kg})$;

To understand the above equation this paper will compute the Root Mean Square Velocity of Hydrogen gas and Oxygen gas as follows.

To compute for Root Mean Square Velocity, this paper will compute the variables in a step by step process as follows, as illustrated by Todd Helmenstine [7], on his paper on the Kinetic Theory of Gasses RMS according to him it follows as,

1) Oxygen gas RMS Velocity computations:

(a) First step is to find the absolute temperature using Celsius to Kelvin conversion formula.

$T={ }^{\circ} \mathrm{C}+273$; Temperature Kelvin conversion

$\mathrm{T}=\left(0^{\circ}\right)+273$; Temperature $\mathrm{T}$ at $0^{\circ}$ Celsius.

$\mathrm{T}=273$ Kelvin; at $\mathrm{T}=0^{\circ}$ Celsius the Temperature Kelvin Value is equal to $273 \mathrm{~K}$.

(b) Second step is to find the Molar Mass in kilograms.

From the Periodic Table, Molar Mass of Oxygen $=16$ $\mathrm{g} / \mathrm{mol}[3]$.

Oxygen gas $(\mathrm{O} 2)$ is composed of two Oxygen atoms bonded together. Therefore,

Molar mass of $(\mathrm{O} 2)=2 \times 16$;

Molar mass of $(\mathrm{O} 2)=32 \mathrm{~g} / \mathrm{mol}$; as follows,

Convert the above values from grams to kilograms

Molar mass of $(\mathrm{O} 2)=(32 \mathrm{~g} / \mathrm{mol}) \times(1 \mathrm{~kg} / 1000 \mathrm{~g})$;
Molar mass of $(\mathrm{O} 2)=32 \times 10^{-3} \mathrm{~kg} / \mathrm{mol}$;

(c) Third step is to find the RMS Velocity value of Oxygen gas as follows.

From the formula as shown and defined in the previous page of this paper, it follows as,

$$
\mu r m s=\sqrt{ }(3 R T / M) ;
$$

Or simple written as follows now substituting the values of $\mathrm{R}, \mathrm{T}$ and $\mathrm{M}$ as defined previously we have the computation as follows.

$\mu \mathrm{rms}=\sqrt{ }(3 \mathrm{RT} / \mathrm{M}) ; \quad($ Oxygen, $\mathrm{O} 2) ;$ $=\sqrt{ }\left\{\left[(3)\left(8.3145 \mathrm{~kg} \cdot \mathrm{m}^{2} / \mathrm{s}^{2} / \mathrm{K} \cdot \mathrm{mol}\right)(273 \mathrm{~K})\right] /[(32 \mathrm{x}\right.$

$\left.\left.\left.10^{-3}\right)\right]\right\}$

$$
\begin{aligned}
& =\sqrt{ }\left\{\left[6.809 \times 10^{3}\right] /\left[32 \times 10^{-3}\right]\right\} ; \\
& =\sqrt{ }\left\{212.799 \times 10^{3} \mathrm{~m}^{2} / \mathrm{s}^{2}\right\} ; \\
& =461.30 \mathrm{~m} / \mathrm{s}
\end{aligned}
$$

$\mu \mathrm{rms}=461 \mathrm{~m} / \mathrm{s} ;$ (Oxygen, O2);

Therefore at a temperature of $\mathrm{T}=0^{\circ}$ Celsius, Oxygen gas tend to travel at an approximate speed or velocity of $\mathrm{v}=$ 461.30 meters per second.

If the temperature increases the speed or velocity of Oxygen gas will also increase accordingly.

2) Hydrogen gas RMS Velocity computations:

(a) First step is to find the absolute temperature using Celsius to Kelvin conversion formula [3].

$$
T={ }^{\circ} \mathrm{C}+273 \text {; Temperature Kelvin conversion }
$$

$\mathrm{T}=\left(0^{\circ}\right)+273$; Temperature $\mathrm{T}$ at $0^{\circ}$ Celsius.

$\mathrm{T}=273 \mathrm{Kelvin}$; at $\mathrm{T}=0^{\circ}$ Celsius the Temperature Kelvin Value is equal to $273 \mathrm{~K}$.

(b) Second step is to find the Molar Mass in kilograms.

From the Periodic Table, Molar Mass of Hydrogen $=1$ $\mathrm{g} / \mathrm{mol}$.

Hydrogen gas (H2) is composed of One Hydrogen atom. Therefore,

Molar mass of $(\mathrm{H} 2)=1 \times 2$;

Molar mass of $(\mathrm{H} 2)=2 \mathrm{~g} / \mathrm{mol}$;

Convert the above values from grams to kilograms as follows,

Molar mass of $(\mathrm{H} 2)=(2 \mathrm{~g} / \mathrm{mol}) \times(1 \mathrm{~kg} / 1000 \mathrm{~g})$;

Molar mass of $(\mathrm{H} 2)=2 \times 10^{-3} \mathrm{~kg} / \mathrm{mol}$;

(c) Third step is to find the RMS Velocity value of Hydrogen gas as follows.

From the formula as shown and defined in the previous page of this paper, it follows as,

$$
\mu r m s=\sqrt{ }(3 R T / M) ;
$$

Or simple written as follows now substituting the values of $\mathrm{R}, \mathrm{T}$ and $\mathrm{M}$ as defined previously we have the computation as follows.

$\mu r m s=\sqrt{ }(3 R T / M) ;$

$\mu \mathrm{rms}=\sqrt{ }(3 \mathrm{RT} / \mathrm{M}) ; \quad$ (Hydrogen, H2);

$=\sqrt{ }\left\{\left[(3)\left(8.3145 \mathrm{~kg} \cdot \mathrm{m}^{2} / \mathrm{s}^{2} / \mathrm{K} \cdot \mathrm{mol}\right)(273 \mathrm{~K})\right] /[(2\right.$ x 10

$\left.\left.\left.{ }^{-3}\right)\right]\right\}$;

$=\sqrt{ }\left\{\left[6.809 \times 10^{3}\right] /\left[2 \times 10^{-3}\right]\right\} ;$

$=\sqrt{ }\left\{3.404 \times 10^{6} \mathrm{~m}^{2} / \mathrm{s}^{2}\right\}$;

$=1,845.12 \mathrm{~m} / \mathrm{s}$;

$\mu \mathrm{rms}=1,845 \mathrm{~m} / \mathrm{s}$; (Hydrogen, H2); 
Therefore, at a temperature of $\mathrm{T}=0^{\circ}$ Celsius, Hydrogen gas tend to travel at an approximate speed or velocity of $\mathrm{v}=$ 1,845 meters per second, as can be shown as follows.

$\mu \mathrm{rms}=1,845 \mathrm{~m} / \mathrm{s}$; (Hydrogen, H2);

If the temperature increases the speed or velocity of Hydrogen gas will also increase accordingly [3].

And now therefore this paper will put the results in a table to make illustrations simple and easy to understand as can be shown as follows.

TABLE I: RMS VELOCITY VALUES OF HYDROGEN AND OXYGEN RESPECTIVELY

\begin{tabular}{ccccc}
\hline \hline $\begin{array}{c}\text { Gas } \\
\text { Element } \\
(\mathrm{Gas})\end{array}$ & $\begin{array}{c}\mathrm{R} \\
\left(\mathrm{kg} \cdot \mathrm{m}^{2} / \mathrm{s}^{2} / \mathrm{K} . \mathrm{mol}\right)\end{array}$ & $\begin{array}{c}\mathrm{T}(\mathrm{T}= \\
273 \\
\mathrm{~K})\end{array}$ & $\begin{array}{c}\text { Molar Mass } \\
(\mathrm{Kg} / \mathrm{mol})\end{array}$ & $\begin{array}{c}\text { RMS } \\
\text { Velocity } \\
(\mathrm{m} / \mathrm{s})\end{array}$ \\
\hline $\begin{array}{c}\text { Oxygen } \\
(\mathrm{O} 2)\end{array}$ & 8.3145 & 273 & $32 \times 10^{-3}$ & 461 \\
\hline $\begin{array}{c}\text { Hydrogen } \\
(\mathrm{H} 2)\end{array}$ & 8.3145 & 273 & $2 \times 10^{-3}$ & 1,845 \\
\hline $\begin{array}{c}\text { Oxygen } \\
(\mathrm{O} 2)\end{array}$ & 8.3145 & 273 & $32 \times 10^{-3}$ & 461 \\
\hline \hline
\end{tabular}

And now this paper was able to show the RMS Velocity Values of the Hydrogen and Oxygen gas. Therefore this paper will now illustrate the RMS Velocity of the combination of Hydrogen and Oxygen gas as produced by the Water Molecule Power Reactor System [5], [6]. To calculate the RMS Velocity of $\mathrm{H} 2 \mathrm{O}$ this paper will use the following formula as follows.

$R M S$ Velocity $(H 2 O)=([R M S H 2])+([R M S$ O2] / [2 atom $]) ;$

Since there are one Oxygen atoms and two Hydrogen atoms in One Molecule of pure water, therefore to compute the RMS Velocity of $\mathrm{H} 2 \mathrm{O}$, it can be shown as follows.

RMS Velocity $(\mathrm{H} 2 \mathrm{O})=([\mathrm{RMS} \mathrm{H2}])+([\mathrm{RMS} \mathrm{O2]} /[2]) ;$

$$
\begin{aligned}
& =([1,845 \mathrm{~m} / \mathrm{s}])+([461 \mathrm{~m} / \mathrm{s}] /[2 \text { atom }]) ; \\
& =(1,845 \mathrm{~m} / \mathrm{s})+(230.5 \mathrm{~m} / \mathrm{s}) ; \\
& =(2,075.5 \mathrm{~m} / \mathrm{s}) ;
\end{aligned}
$$

RMS Velocity $(\mathrm{H} 2 \mathrm{O})=2,075.5 \mathrm{~m} / \mathrm{s}$; (Pure Water H2O);

TABLE II. RMS VELOCITY VALUE OF $\mathrm{H}_{2} \mathrm{O}$ (GAS FORM)

\begin{tabular}{ccccc}
\hline \hline $\mathrm{H}_{2} \mathrm{O}$ & $\begin{array}{c}\mathrm{R} \\
\left(\mathrm{kg} \cdot \mathrm{m}^{2} / \mathrm{s}^{2} / \mathrm{K} \cdot \mathrm{mol}\right)\end{array}$ & $\begin{array}{c}\mathrm{T} \\
(\mathrm{T}=273 \mathrm{~K})\end{array}$ & $\begin{array}{c}\text { Molar Mass } \\
(\mathrm{Kg} / \mathrm{mol})\end{array}$ & $\begin{array}{c}\text { RMS Velocity } \\
(\mathrm{m} / \mathrm{s})\end{array}$ \\
\hline $\mathrm{H}_{2} \mathrm{O}$ & 8.3145 & 273 & $18 \times 10^{-3}$ & $2,075.5$ \\
$\mathrm{H}_{2} \mathrm{O}$ & 8.3145 & 273 & $18 \times 10^{-3}$ & $2,075.5$ \\
\hline \hline
\end{tabular}

To convert meters to kilometers into RMS Velocity Value of $\mathrm{H} 2 \mathrm{O}$ (gas form), this paper will show the computation as follows.

RMS Velocity $(\mathrm{H} 2 \mathrm{O})=2,075.7 \mathrm{~m} / \mathrm{s}$; (Pure Water H2O, gas form);

RMS Velocity $(\mathrm{H} 2 \mathrm{O})=2,075.7 \mathrm{~m} / \mathrm{s}$;

$$
\begin{aligned}
& =(2,075.7 \mathrm{~m} / \mathrm{s}) \times(1 \text { kilometer } / 1000 \text { meters }) ; \\
& =2.075 \mathrm{kilometers} / \text { second; }
\end{aligned}
$$

RMS Velocity $(\mathrm{H} 2 \mathrm{O})=2.075 \mathrm{~km} / \mathrm{s}$; (Pure Water H2O, gas form);

The RMS Velocity $(\mathrm{H} 2 \mathrm{O})=2.075 \mathrm{~km} / \mathrm{s}$, is based on the Temperature of $\mathrm{T}=0^{\circ}$ Celsius the Temperature Kelvin Value is equal to $273 \mathrm{~K} \mathrm{[3].} \mathrm{As} \mathrm{the} \mathrm{Temperature} \mathrm{increases}$ the velocity also increase with respect to time in seconds.

Therefore, if Pure Water is converted to its gas form which is $\mathrm{H} 2 \mathrm{O}$, and if this $\mathrm{H} 2 \mathrm{O}$ is ignited then this $\mathrm{H} 2 \mathrm{O}$ gas will travel to a velocity of approximately $2.075 \mathrm{~km} / \mathrm{s}$ or $2.075 \times 10^{3}$ meters/second. Wow this is very interesting to be used as a fuel to drive certain mass from one point to another.
Now this paper will compute the Force that is created by the burning of hydrogen and oxygen gas as a product of water inside the Water Molecule Power Reactor System. To compute for the force this paper will recall the formula of force as defined earlier and the formula of average acceleration as follows [1].

$$
\begin{aligned}
& F=m a ;(\text { Horizontal Movement, X Coordinates) } \\
& a_{a v}=\left(V_{2}-V_{1}\right) /(t 2-t 1) ;
\end{aligned}
$$

If this paper will compute the force, it must first compute the value of acceleration as follows.

$$
a a v=\left(V_{2}-V_{1}\right) /(t 2-t 1)
$$

From the computations above of RMS Velocity $(\mathrm{H} 2 \mathrm{O})=$ $2.075 \mathrm{~km} / \mathrm{s}$; (Pure Water H2O, gas form), it can be assumed that,

$$
\begin{aligned}
\mathrm{V} 2=2.075 \mathrm{~km} / \mathrm{s} ; & \mathrm{V} 1=0 ; \\
\mathrm{t} 2=1 \mathrm{sec} ; & \mathrm{t} 1=0 \mathrm{sec}
\end{aligned}
$$

Substitute the above values to the formula of average acceleration $\mathrm{a} a v=(\mathrm{V} 2-\mathrm{V} 1) /(\mathrm{t} 2-\mathrm{t} 1)$ as shown.

$$
\begin{aligned}
\mathrm{a} a v & =(\mathrm{V} 2-\mathrm{V} 1) /(\mathrm{t} 2-\mathrm{t} 1) ; \\
& =(2.075 \mathrm{~km} / \mathrm{s}-0 \mathrm{~km} / \mathrm{s}) /(1 \mathrm{sec}-0 \mathrm{sec}) ;
\end{aligned}
$$

$\mathrm{a} a v=2.075 \mathrm{~km} / \mathrm{s}$ or $2.075 \times 10^{3}$ meters/second; (average acceleration);

Substitute the above acceleration value to the formula of force, $\mathrm{F}=\mathrm{ma}$, and assume the value of $\mathrm{m}=1 \mathrm{kilogram}(\mathrm{kg})$, thus it can be shown as follows [1].

$$
F=m a ; \text { (Horizontal Movement, } \mathrm{X} \text { Coordinates) }
$$

$$
\begin{aligned}
\mathrm{F} \quad & =\mathrm{m} \mathrm{a} ; \quad \text { (Force) } \\
& =(1 \mathrm{~kg})\left(2.075 \times 10^{3} \mathrm{~m} / \mathrm{s}\right) ; \\
& =\left(2.075 \times 10^{3} \mathrm{~kg} . \mathrm{m} / \mathrm{s}\right) ; \\
& =2.075 \times 10^{3} \text { Newton, } \mathrm{N} ;
\end{aligned}
$$

$\mathrm{F}=2.075 \times 10^{3} \mathrm{~N} ;$ (Equivalent Force meters/second);

$\mathrm{F} \quad=2.075$ Kilo Newton; (Equivalent Force, kilometers/second);

The above value of force is the equivalent force produced by a single molecule of water $\mathrm{H} 2 \mathrm{O}$.

TABLE III. RMS VELOCITY, AVERAGE VELOCITY AND FORCE VALUES OF H2O (GAS FORM)

\begin{tabular}{cccc}
\hline \hline $\mathrm{H}_{2} \mathrm{O}$ & $\begin{array}{c}\text { RMS Velocity } \\
(\mathrm{m} / \mathrm{s})\end{array}$ & $\begin{array}{c}\text { Average } \\
\text { Acceleration a } a v\end{array}$ & Force $(\mathrm{Kg} \cdot \mathrm{m} / \mathrm{s})$ \\
\hline $\mathrm{H}_{2} \mathrm{O}$ & $2,075.5$ & $2.075 \times 10^{3} \mathrm{~m} / \mathrm{s}$ & $2.075 \times 10^{3} \mathrm{~N}$ \\
\hline
\end{tabular}

Unlike in fuel cells which converts hydrogen gas and oxygen gas to electricity through chemical reactions, in this study the energy produced by water molecule is being considered in its purest form since the energy potential of pure hydrogen and oxygen upon introduction of fire and flame is the prime concern in this study which will be utilized in the jet engine propulsion. 


\section{CORRELATION OF RESUlTS}

\section{A. Correlation of the Principles of Thrust and the} Principles of Root Mean Square Velocity

In this section the paper will now discuss the relationship of the Principles of Thrust to that of the Principles of Root Mean Square Velocity as follows as defined earlier in the discussion.

The formula of thrust is as follows as shown below as illustrated earlier [1].

$$
T=v(d m / d t) ;(Z \text { Coordinates })
$$

Where:

$T=$ Thrust Generated, (Force), Kilograms or Newton;

$v=$ Speed of the exhaust gases, (Meters per Seconds);

$d m / d t=$ Rate of Change of Mass with Respect to Time;

From the values of Table III. RMS Velocity $(\mathrm{m} / \mathrm{s})$, then the value of RMS Velocity of $\mathrm{H} 2 \mathrm{O}$ is equal to RMS Velocity $(\mathrm{H} 2 \mathrm{O})=2,075.5 \mathrm{~m} / \mathrm{s}$. Substituting this value to the Thrust formula and assuming the mass value of water is 1000 grams or 1 liter of pure water. Then it can be shown as follows.

Given values as shown,

Velocity $=$ RMS Velocity $(\mathrm{H} 2 \mathrm{O})=2,075.5 \mathrm{~m} / \mathrm{s}$;

Mass $=$ mass $(\mathrm{m})$ of water is from $\mathrm{m} 1=1000$ grams and $\mathrm{m} 2=0$ grams assuming;

Time $=$ Time $(\mathrm{t})$ is from $\mathrm{t} 2=1$ second and $\mathrm{t} 1=0$ second respectively;

Substitute to the formula of Thrust [1],

$$
T \quad=v(d m / d t) ;(\mathrm{Z} \text { Coordinates })
$$

$\mathrm{T}=[2,075.5 \mathrm{~m} / \mathrm{s}] \mathrm{X}[(0 \mathrm{~kg})-(1000 \mathrm{~kg}) /(1 \mathrm{~s})-(0 \mathrm{~s})] ;$

$\mathrm{T} \quad=[2,075.5 \mathrm{~m} / \mathrm{s}] \mathrm{X}[(-1000 \mathrm{~kg}) /(1 \mathrm{~s})] ;$

$\mathrm{T} \quad=[2,075.5 \mathrm{~m} / \mathrm{s}] \mathrm{X}[-1000 \mathrm{~kg} / \mathrm{s}]$;

$\mathrm{T} \quad=\left[-2,075,500 \mathrm{~kg} \cdot \mathrm{m} / \mathrm{s}^{2}\right]$

$\mathrm{T}=-2,075,500 \mathrm{~kg} \cdot \mathrm{m} / \mathrm{s}^{2}$;

$\mathrm{T} \quad=-2,075.5 \mathrm{~kg} \cdot \mathrm{km} / \mathrm{s}^{2}$;

$\mathrm{T}=-2,075.5 \mathrm{~km} . \mathrm{kg} / \mathrm{s}^{2}$; Therefore, the equivalent Thrust is 2,075 kilometers per seconds squared for a 1000 grams of water fuel. It is negative because it is decreasing through the span of time. This Thrust is at $\mathrm{T}=0^{\circ}$ Celsius or 273 Kelvin [3]. As the Temperature increases the Thrust will also increase thereby compensating on the loss of fuel with an equivalent increase in the propulsion of the jet engine.

To summarize the facts as follows, as the fuel decreases with time the thrust increases with the increase of temperature with also respect to time.

Now this paper will differentiate this Thrust with respect to the Speed of Sound which is equal to $331.29 \mathrm{~m} / \mathrm{s}$. Now this paper will divide the value of Thrust with respect to the Speed of Sound.

$$
\begin{aligned}
\mathrm{T} & =\left(-2,075.5 \mathrm{~kg} \cdot \mathrm{km} / \mathrm{s}^{2}\right) /(\text { Speed of Sound }) ; \\
\mathrm{T} & =\left(-2,075.5 \times 10^{3} \mathrm{~kg} \cdot \mathrm{m} / \mathrm{s}^{2}\right) /(331.29 \mathrm{~m} / \mathrm{s}) ; \\
\mathrm{T} & =6.264 \times 10^{3} \text { per second faster than the speed of }
\end{aligned}
$$
sound.

Therefore, this paper can say that the Thrust produced by a single molecule of water is capable of producing a thrust that is $6.264 \times 10^{3}$ faster than the speed of sound.
In this study it will be noted that thrust is directly inversely variable to the weight of the object being pushed upward. Thus to put this in the mathematical form it can be shown as follows

$$
\begin{aligned}
& \mathrm{T}=\mathrm{v}(\mathrm{dm} / \mathrm{dt}) ; \\
& \mathrm{T}=[\mathrm{v}(\mathrm{dm} / \mathrm{dt})] /[\text { Weight of the Object }] ;
\end{aligned}
$$

For example, the weight of the object being pushed upward is 50 kilograms then it can be shown that.

$$
T=[v(d m / d t)] /[\text { Weight of the Object }] \text {; }
$$

$\mathrm{T}=\left[-2,075.5 \mathrm{~kg} . \mathrm{km} / \mathrm{s}^{2}\right] /[50$ kilograms $]$;

$\mathrm{T}=41.51 \mathrm{~km} / \mathrm{s}^{2}$;

$\mathrm{T}=41.51 \mathrm{~km} / \mathrm{s}^{2}$; this new value of thrust represents the net thrust due to the weight of the object being pushed upward.

\section{B. Principles of Jet Propulsion and Thrust}

Based on the derived values of Thrust which is equal to as calculated to be as follows,

$\mathrm{T} \quad=-2,075.5 \mathrm{~kg} \cdot \mathrm{km} / \mathrm{s}^{2}$;

This value of Thrust is $6.264 \times 10^{3}$ faster than the speed of sound.

The importance of these respective values is very relevant and significant to the present study for it entails the great potential of one liter of water as being a good fuel for planetary and interplanetary travel. If a molecule one liter of water is capable of producing a Thrust of $\mathrm{T}=2,075.5$ $\mathrm{kg} . \mathrm{km} / \mathrm{s}^{2}$ at $\mathrm{T}=0^{\circ}$ Celsius or 273 Kelvin [3], then this water molecule can therefore accelerate an object into surface of the planet and greatly possible into outer space above the surface of the earth.

Furthermore, this paper will simplify the value of the derived Thrust into a more comprehensive perspective as follows.

$\mathrm{T} \quad=-2,075.5 \mathrm{~kg} \cdot \mathrm{km} / \mathrm{s}^{2}$;

This paper will divide the above value of thrust by 1 second $=1000 \mathrm{~kg}$ of water or one liter.

$\mathrm{T} \quad=-2,075.5 \mathrm{~kg} . \mathrm{km} / \mathrm{s}^{2}$;

$\mathrm{T} \quad=\left(-2,075.5 \mathrm{~kg} \cdot \mathrm{km} / \mathrm{s}^{2}\right) /(1 \mathrm{~s} / 1000 \mathrm{~kg}$ or 1 liter $)$;

$\mathrm{T}=-2.075 \mathrm{~km} / \mathrm{s}$; this value becomes the distance per second traveled by a one-liter molecule of water energy fuel.

Again the above value is very significant and very important as this paper endeavors to evaluate the full potential of hydrogen gas and oxygen gas produced by the Water Molecule Power Reactor in relation to its application in the planetary and interplanetary travel using jet engine propulsion technology.

\section{Planetary and Interplanetary Travel Applications}

As mentioned in the previous section of this papers discussions, with the values of Thrust and the distance that the Thrust can reach is very significant and very relevant to this study of the potential present and future application of the Water Molecule Power Reactor System to transform the water molecule into the hydrogen gas and oxygen gas that is capable of a Thrust of computed value of $\mathrm{T}=2,075.5$ $\mathrm{kg} . \mathrm{km} / \mathrm{s}^{2}$ and an equivalent distance reach of distance value of $\mathrm{D}=2.075 \mathrm{~km} / \mathrm{s}$ for one liter of pure water in one second. 
Now in every one hour there is 3600 seconds and if this paper will multiply $\mathrm{D}=2.075 \mathrm{~km} / \mathrm{s}$ by $3600 \mathrm{~s} / 1$ hours then it follows as shown.

$\mathrm{D}=2.075 \mathrm{~km} / \mathrm{s}$

$\mathrm{D}=(2.075 \mathrm{~km} / \mathrm{s}) \times(3600$ seconds $/ 1$ hour $)$;

$\mathrm{D}=7,470 \mathrm{~km} /$ hour; Total Thrust without Load weights;

$\mathrm{D}=(7,470 \mathrm{~km} /$ hour $) /(1000$ grams of weight $)$;

$\mathrm{D}=7.47 \mathrm{~km} /$ hour.

Therefore, if water molecule is used as a fuel in a jet engine, the jet engine can reach nearly the stratosphere which is about approximately $12 \mathrm{~km}$ to $50 \mathrm{~km}$ above the sea level in a single hour by the next hour the jet engine would be $14 \mathrm{~km}$ in the stratosphere already.

Therefore, if commercial airlines can travel the troposphere which is at $12 \mathrm{~km}$ from above sea level then the use of water fuel for jet engine propulsion is very feasible and possible with a speed more than the speed of sound the jet engine will be traveling at more than a supersonic speed, given of course that all mathematical parameters had been considered.

Other mathematical parameters are always valuable points to consider in any scientific undertakings thus it will be prudent to examine essential mathematical parameters foreseeable relative to the planetary and interplanetary travel applications of the Water Molecule Power Reactor System research initiative.

\section{CONCLUSION}

In this study the thrust and velocity of a single molecule of water have been studied and evaluated in relation to its great potential as a fuel in the jet engine propulsion technology and based on the results of the computation, it is affirmative to conclude that indeed water molecule, if transformed to its individual atomic constituents of hydrogen gas and oxygen gas can be significantly used as a fuel to power jet engines to accelerate to an approximate speed or velocity of $\mathrm{V}=2,075.5 \mathrm{~km} / \mathrm{s}^{2}$ for a one liter of pure water and can reach a distance of $\mathrm{D}=2.075 \mathrm{~km} / \mathrm{s}$ for one liter of water fuel in a given time span of one second.

Since from the previous studies it was identified that a one liter of water fuel can last up to one hour then this paper can multiple the distance value, reached in one second to be multiplied by a value of 3600 seconds for one hour, as can be shown as follows.

$\mathrm{D}=2.075 \mathrm{~km} / \mathrm{s}$

$\mathrm{D}=(2.075 \mathrm{~km} / \mathrm{s}) \times(3600 \mathrm{sec} / 1$ hour $)$;

$\mathrm{D}=7,470 \mathrm{~km} /$ hour; this value represents the distance in which one liter of water fuel can reach for a time span of one hour. This value as shown above is calculated and was derived without the weight of the load being carried by the jet engine with a gross or unloaded total value of thrust of $\mathrm{T}$ $=-2,075.5 \mathrm{~kg} \cdot \mathrm{km} / \mathrm{s}^{2}$. The net thrust can be calculated based on the following assumption as follows as previously discussed on this paper.

$$
T=[v(d m / d t)] /[\text { Weight of the Object }] \text {; }
$$

The weight of the object being propelled and pushed upward against gravity greatly decreases the value of thrust however the energy produced by the hydrogen gas and oxygen gas creates a significant balance into the upward force and downward force.

Therefore, the upward force must be twice or more than greater than the downward force which is in this study had been able to successfully show that the needed upward force is much greater than the downward force.

\section{ACKNOWLEDGEMENT}

The author's wishes to give thanks to the Creator for making this research work possible. An enormous and significant time has been dedicated in the full completion of this research work and the efforts for this research initiative continuous through time thus, the author acknowledges the gift of time and opportunity given by the great and almighty Creator.

\section{REFERENCES}

[1] H. D. Young \& R. A. Freedman. University Physics with Modern Physics. $14^{\text {th }}$ Edition. Singapore: Pearson Education Asia Pte. Ltd., 2016. pp. 731-1025

[2] D. E. Johnson, J. R. Johnson, \& J. L. Hilburn. Electric Circuit Analysis. $2^{\text {nd }}$ Edition. New Jersey: Prentice Hall, 1992. pp. 1-53.

[3] G. B. King, W. E. Cadwell \&, M. B. Williams. College Chemistry. 7th Edition. New York: Litton Educational Publishing, Inc. 1977. pp. $2-410$.

[4] Webster's Dictionary. Webster's Universal Dictionary and Thesaurus. Scotland: Geddes \& Grosset, 2002. pp. 11-571.

[5] C.J.G. Ecle, F.O. Abrera, A.A.S. Araneta, C.A. Bolito, A.M. Duran, L.R.L. Alforte, A.D. Ranido, J.G. Ocana, "Design of a Hydrogen and Oxygen Power Reactor using Pure Water (H2O) and a Modified Electrolysis Process and Procedures", IJSBAR, vol.51, no.1, 2019. Available:

https://www.gssrr.org/index.php/JournalOfBasicAndApplied/article/v iew/11021/5618

[6] C.J.G. Ecle, F.O. Abrera, A.A.S. Araneta, C.A. Bolito, A.M. Duran, L.R.L. Alforte, A.D. Ranido, "Analysis of the Electron Phenomena inside the Water Molecule Power Reactor System", The IJES, vol. 9, no. 5, 2019. Available:

http://www.theijes.com/papers/vol9-issue5/Series-1/F0905014551.pdf

[7] Helmenstine, T. ,"Calculate Root Mean Square Velocity of Gas Particles.",https://www.thoughtco.com/kinetic-theory-of-gas-rmsexample-609465?print, 30 January 2020.

Cornelio Jeremy G. Ecle, MIT, Research Team Leader, Faculty of the College of Computer Studies, Eastern Samar State University, Salcedo Campus, Salcedo Eastern Samar, Philippines. Personal Website www.systenext.com Email: jeremyecle2015@yahoo.com

Fedeliza O. Abrera, MIT, Research Team Member, Faculty of the College of Computer Studies, Eastern Samar State University, Salcedo Campus, Salcedo Eastern Samar, Philippines. Email: fedessabrera@yahoo.com.ph

Dr. Arvin Anthony S. Araneta, DMT, Research Team Member, Faculty of the College of Computer Studies, Eastern Samar State University, Salcedo Campus, Salcedo Eastern Samar, Philippines. Email: arvin.araneta@gmail.com

Cherlowen A. Bolito, MAT-MATH, Research Team Member, Faculty Member, Eastern Samar State University, Salcedo Campus, Salcedo Eastern Samar, Philippines. Email: drrmessusalcedo@gmail.com.

Archibald M. Duran, MIT, Research Team Member, Faculty of the College of Computer Studies, Eastern Samar State University, Salcedo Campus, Salcedo Eastern Samar, Philippines. Email archie5_927@yahoo.com.ph.

Loren Rose L. Alforte, MIT, Research Team Member, Faculty of the College of Computer Studies, Eastern Samar State University, Salcedo Campus, Salcedo Eastern Samar, Philippines. Email: lorenrosealforte2020@yahoo.com

Arnold R. Balano, Research Team Member, College IT Technician, College of Computer Studies, Eastern Samar State University, Salcedo Campus, Salcedo Eastern Samar, Philippines. Email: arnold_balano18@yahoo.com.

Archibal D. Ranido, MIT, Research Team Member, Faculty Member, Eastern Samar State University, Guiuan Campus, Guiuan, Eastern Samar, Philippines. Email: archibalranidog1@gmail.com. 